\title{
First Record of Dicephalism in the Banded Kukri, Oligodon arnensis (Shaw 1802), from Nepal
}

\author{
Kamal Devkota ${ }^{1,2}$, Santa Bahadur Magar ${ }^{3}$, Van Wallach ${ }^{4}$, and David Wojnowski ${ }^{2,5}$ \\ ${ }^{1}$ Nepal Toxinology Association, Kawasoti, Nawalpur, Nepal (devkotakamal67@gmail.com) \\ ${ }^{2}$ Save The Snakes, 2929 35th St \#5402, Sacramento, California 95817, USA \\ ${ }^{3}$ Chitwan National Park, Kasara, Chitwan, Nepal \\ ${ }^{4} 4$ Potter Park, Cambridge, Massachusetts 02138, USA \\ ${ }^{5}$ Department of Early Childhood and Elementary Education, College of Education \& Human Development, Georgia State University, Atlanta, Georgia 30303, USA
}

$\mathrm{T}$ he latest tabulation of verified cases of axial bifurcation in snakes lists 2,007 cases, including 221 species in 114 genera; if one includes anecdotal reports the total number of cases rises to 2,071 (V. Wallach, unpubl. data). A total of 600 cases of dicephalism have been documented in the family Colubridae (sensu lato; V. Wallach, unpubl. data), including two species of Oligodon from Thailand: O. joynsoni (Nutphand 1998) and O. barroni (D. Sweerland 1999, unpubl. data). Herein we report the first case of dicephalism in the Banded Kukri (Oligodon arnensis).

Dicephalic snakes rarely survive long in nature (Wallach 2018). So, as with all individuals captured in the wild, the snake in question is a recently hatched proarchodichotomous neonate (Fig. 1) with two long necks that are united at the anterior quarter of the body. The junction of the two necks with the body exhibits a smooth transition and lacks the normally seen enlargement or kinking of the spine. The left neck is slightly longer than the right, constituting $26.5 \%$ of SVL (or $22 \%$ of total length), whereas the right neck is $25.4 \%$ of SVL (or $21 \%$ of total length) (percentages are based on measurements from Fig. 1 and utilize a mean relative tail length ratio of $16.5 \%$, fide De et al. 2018). This suggests that the left neck has 1 or 2 more vertebrae than the right neck.

This dicephalic Banded Kukri was captured by local villagers in October 2018 near Daldale, Devchuli Municipality, Nawalpur District, Gandaki Province, Nepal

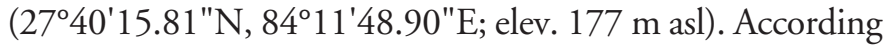
to park rangers from Kasara, Chitwan National Park (Santa Bahadur Magar and Amrita Pudasaini), local people were carrying the snake from Nawalpur to Kathmandu. The snake was rescued by police officers and transferred to the park rangers, who subsequently released it into natural habitat. During the release, team members were able to observe its behavior. According to them, the snake was having difficulty crawling smoothly and moved very slowly. This is a normal condition for newborn dicephalic snakes because each head is independent of the other and each has its own mind about where to go, resulting in a jerky back-and-forth struggle to control the body. The inability to crawl normally in a coordinated manner inevitably will result in the animal's death as it cannot successfully escape predators or capture food. The

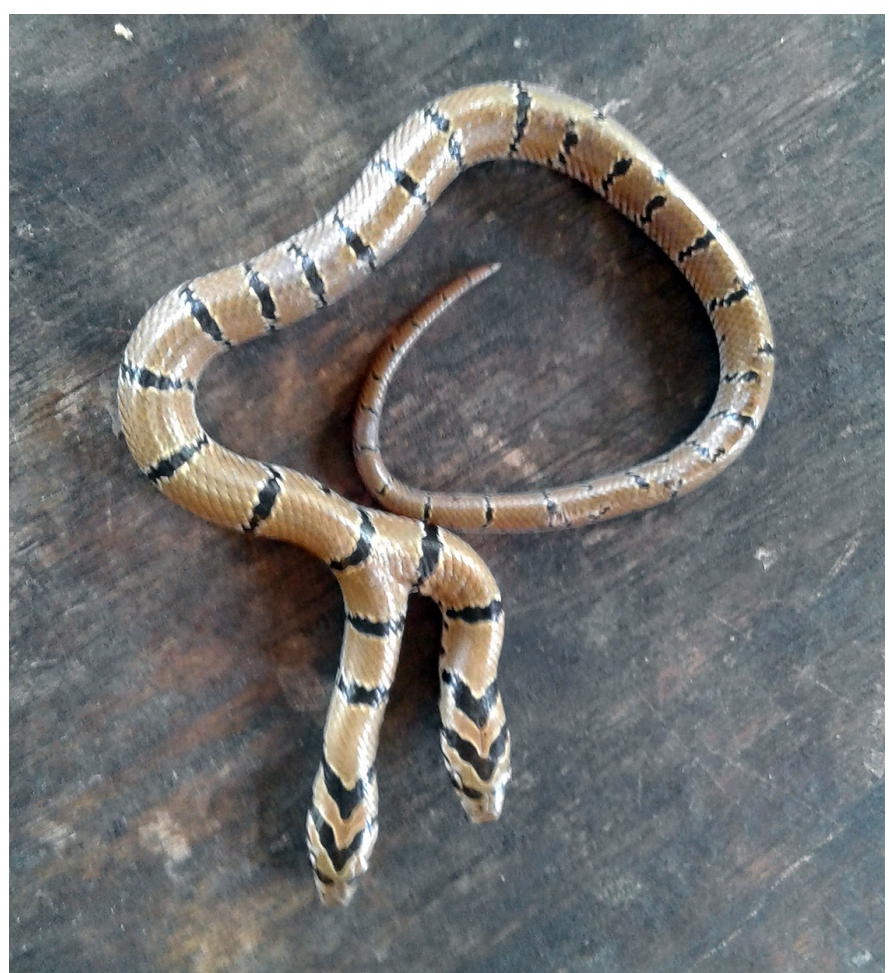

Fig. 1. A neonatal dicephalic Banded Kukri (Oligodon arnensis) from Nepal. Photograph provided by Kasara, Chitwan National Park. 
only chance for survival of two-headed snakes is to live in captivity. Because the living individual was released, we were unable to acquire any detailed information. However, digital voucher images were deposited in Lee Kong Chain Natural History Museum, National University of Singapore (cat. no. ZRC(IMG) 2.422a,b).

Two previous reports documented two-headed snakes from Nepal. Mishra and Shah (1983) described a juvenile Checkered Keelback (Fowlea piscator), which was deposited in the Natural History Museum of Nepal. Devkota et al. (2020) reported a neonatal Common Krait (Bungarus caeruleus), with digital voucher images deposited in Lee Kong Chain Natural History Museum, National University of Singapore (cat. no. ZRC(IMG) 2.407a,b). This most recent addition to the list of two-headed snakes represents the first documented case of dicephalism in Oligodon arnensis worldwide and the third record of dicephalism from Nepal.

\section{Acknowledgements}

We thank Ranger Amrita Pudasaini and Gamescout Gam Bahadur Ghalan from Kasara, Chitwan National Park; Dr. Chhabilal Thapa Magar and Dr. Amod Ghimire from Nepal Toxinology Association, Kawasoti, Nawalpur; and Sunil
Tamang and Bimal Pariyar for providing us detailed information of the species without which this study would not have been possible. The first author also thanks The Rufford Foundation, UK, for funding fieldwork (Project numbers: 19206-1 and 23145-2) while working a "Save Snakes Save Nature" project in Nepal, during which the information presented in this note was found. We also thank the Natural History Museum of Nepal and Save The Snakes. We are thankful to the Department of Forest and Soil Conservation and Department of National Park and Wildlife Conservation (DNPWC), Babarmahal, Kathmandu for granting permission to conduct this study.

\section{Literature Cited}

De, P., S. Bkahat, and A.K. Sinha. 2018. Redescription of Oligodon arnensis, Shaw, 1802 (Reptilia: Colubridae) collected from Birbhum, West Bengal, India. Indian Journal of Pharmaceutical and Biological Research 6(1): 42-47.

Devkota, K., A. Ghimire, C. Thapamagar, V. Wallach, and D. Wojnowski. 2020. First record of dicephalism in the Common Krait, Bungarus caeruleus (Schneider 1801), from Nepal. Reptiles \& Amphibians 26: 226-229.

Mishra, P.N. and K.B. Shah. 1983. Notes on two headed snake. Journal of Natural History Museum 7: 101-103

Nutphand, W. 1998. Two-headed snakes. Bulletin of the Thai Zoological Center, Bangkok 3(11):111-124 (in Thai).

Wallach, V. 2018. Axial bifurcation and duplication in snakes. Part VI. A 10-year update on authentic cases. Bulletin of the Chicago Herpetological Society 53: 1-20. 